\title{
Role of alternate healthy eating index (AHEI) in communicating the quality of diet
}

\author{
Krishna Mohandas and L. Prema
}

\begin{abstract}
Introduction: The food habits of global population has been evolving in such a way that makes unhealthy foods cheaper and widely available and healthy foods costly and less available. Being surrounded by such foods and living in an environment with lesser requirement for physical activity is the primary reason for the pandemic explosion in overweight and obesity. This study is an attempt to analyze the quality of diet with an aim to study the significance of Alternate Healthy Eating Index (AHEI) in predicting the quality of dietary intake. Methodology: The study was conducted in 66 respondents ( 44 females and 22 males) aged 18-65 years with BMI between $23 \mathrm{~kg} / \mathrm{m}^{2}$ to $50 \mathrm{~kg} / \mathrm{m}^{2}$. The respondent's data were collected using a pretested standard questionnaire. The nutrient consumption was calculated from the 24 hour recall and the AHEI scores were derived from recall and food use frequency data. The data were analysed using SAS software. Results: The intake of Energy, protein, fat and carbohydrates were more than their requirement while intake of fibre was not meeting the requirement. The AHEI scores obtained ranged from 36 to 76 with a mean value of $55.6 \pm 9.54$. A positive linear association for AHEI with BMI (0.0362) and energy intake (0.13) was established through Pearson's correlation while the association was negative with BMR (-0.14). Paired $t$ test comparing AHEI against the difference between intake and requirement of macronutrients revealed that when the diet quality was good (as indicated by AHEI $>51$ ), the difference in intake exhibited a significant linear relationship with $p$ values $<0.001$ while no relation was established when the diet quality was poor. Conclusion: AHEI encompasses all nutrients and food groups relevant to metabolic health and it can be used as a good tool to assess the quality of dietary habits of overweight and obese subjects.
\end{abstract}

Key Words : Alternate healthy eating index, Quality of diet, Overweight, Obesity, Quality of diet

How to cite this article : Mohandas, Krishna and Prema, L. (2020). Role of alternate healthy eating index (AHEI) in communicating the quality of diet. Food Sci. Res. J., 11(2): 96-102, DOI : 10.15740/HAS/FSRJ/11.2/96-102 .Copyright@ 2020: Hind Agri-Horticultural Society.

MEMBERS OF RESEARCH FORUM

Author for correspondence :

Krishna Mohandas, Department of Food and Nutrition, Kerala

University, Thiruvananthapuram (Kerala) India

Email: krishnamohandas@yahoo.co.in

Associate Authors' :

L. Prema, Department of Home Science, College of Agriculture, Vellayani (Kerala) India 